\title{
The Research of the University's Core Competitiveness Based on the Quality of Talent Training
}

\author{
Liu Xia, Zou Jiancheng \\ Office of Planning \& Policy Research, North China University of Technology \\ No.5 Jinyuanzhuang Road, Shijingshan District \\ Beijing, China \\ liuxia@ncut.edu.cn, zjc@ncut.edu.cn
}

\begin{abstract}
The quality of talent training is an important index to measure the university's core competitiveness. There are some important aspects to affect the quality of talent training, such as the development environment, the development strategy, the resource cooperation in talent training and teaching management, etc. Based on the investigation of the core competitiveness of a few top universities in Chinese mainland and North China University of Technology, the following suggestions are proposed in this paper to improve the quality of talent training : (1) positioning accurately and reasonably, forming distinctive and differentiated comparative advantages; (2) focusing on individualized, implementing the reform of talent training modes; (3) paying attention to practice teaching system , improving students' innovative spirit and practical ability; (4) raising the level of teaching management, paying attention to process investigation and ability evaluation, improving teaching quality.
\end{abstract}

Key words: colleges and universities; talent training quality; core competitiveness

\section{Introduction}

Talent training is the chief responsibility and core task of the university. To cultivate first-class talents is a key indicator of bringing out the full potential of higher education in the new era The report of the 19th CPC National Congress laid out a series of major strategic plans for the country, such as the strategy for invigorating China through science and education, the strategy on developing a quality workforce, the innovation-driven development strategy, the rural vitalization strategy, the coordinated regional development strategy, the sustainable development strategy, and the military-civilian integration strategy. We can't implement these strategic plans, or develop education that people are satisfied with, unless we can effectively play the role of higher education in training first-class talents. Therefore, training first-class talents must improve the quality of talent training, which is the inevitable requirement of building China's strength in product quality, especially the requirement of building China's strength in higher education, and is also an important measure to enhance the core competitiveness of colleges and universities.

The modern core competitiveness theory provides theoretical support for bringing out the full potential of colleges and universities. The theory originated in the $1990 \mathrm{~s}$, the representative doctrines are "the core competency of the corporation" and "National competitive strategy to gain competitive advantage". From the perspective of enterprise management, the core competitiveness is based on the technological capabilities of enterprises, which is to coordinate different production skills, combine a variety of technical schools organically to ensure that enterprises have a sustainable competitive advantage. It mainly includes the core technical capability, organization and coordination ability, external influence and resilience, and its essence is to make the consumer get the irreplaceable value, products, services and culture which are really better than that from other competitors [1]. From the perspective of national competition, the competitive advantage based on competitiveness is a source of wealth for a country. The rise and fall of a country depends on whether it can create and maintain a sustained international competitive advantage. The acquisition and maintenance of international competitive advantage depends mainly on whether the state can establish appropriate innovation mechanism and possess strong ability to innovate [2]. It can be seen that establishing lasting competitive advantages for countries, enterprises or individuals stems from utilizing various capabilities comprehensively to better adapt to social development and environmental changes.

At the beginning of the 21 st century, the theory of core competitiveness has been introduced into the field of higher education. Some scholars have classified the definition of the university's core competitiveness as four categories:" competence-based view", " resource-based view ", "synergetic viewpoint" and " elements-based view"[3]. There is a representative point of view: Universities are centered on technical competence, through the integration of strategic decision-making, scientific research and industrialization of its' results, curriculum setup and teaching, human resource development and organization management, or through the highlight one of the elements to gain sustainable competitive advantage [4]. While some scholars believe that, the university's core competitiveness is the ability to utilize and integrate resources such as material, financial and human resources inside and outside the university to obtain high-quality teaching, scientific research and service achievements as well as sustainable competitive advantages $[5]$.

The university's core competitiveness refers to keeping the sustainable development of competitiveness by focusing on the quality of talent training, analyzing the development environment, formulating the development strategy, integrating all aspects of school resources and forming a unique school-running mechanism. Specifically, the mode of talent training is the foundation of the university's core 
competitiveness, talent training should reflect the training specifications and requirements of compound talents; students' innovative ability is the key to the university's core competitiveness, which reflecting the quality of talent training in colleges and universities directly; education and teaching reform is the guarantee of the university's core competitiveness, including the school teaching system, teaching methods, teaching evaluation and so on. The report of the 19th CPC National Congress put forward the new task of "bringing out the full potential of higher education", which requires colleges and universities, under the guidance of the scientific concepts in educational quality, form a distinctive mode of talent training, enhance students' ability in practice and innovation, improve educational and teaching management system, cultivate and strengthen the university's core competitiveness.

\section{The Development of the Core Competitiveness of the Top Universities in Chinese Mainland}

Top universities in Chinese mainland adopt the college system, plan of top-notch innovative talents and so on to cultivate high-quality talents. The college system adopts the combination of general education and professional education, the junior students receive basic education and general education, and the senior students receive wide-caliber professional education, meanwhile the credit system of free course-choosing and independent choosing major system are implemented to achieve two-way choice and diversion. Such as Yuanpei College of Peking University, YAT-SEN School of Sun Yat-sen University, Kuang Yaming Honors School of Nanjing University and so on. Top-notch innovative talents are equipped with mentors, seminars, inviting renowned professors to teach classes, sponsoring students to carry out academic research and implementing the system of selecting and withdrawing of the outstanding students. Such as Tsinghua University, Fudan University, Shanghai Jiao Tong University.

The top universities in Chinese mainland cultivate students' innovative ability and practical ability mainly by carrying out practice teaching and implementing entrepreneurship and innovative education. Practice teaching mainly includes two aspects: course teaching and extracurricular practice. The former focuses on experimental teaching, curriculum, practical training, and graduation thesis. While the latter mainly focuses on scientific research projects, science and technology competitions and social practice. Entrepreneurship and innovative education is carried out mainly through the establishment of entrepreneurial courses, the implementation of innovation and entrepreneurship training programs, as well as the creation of innovative entrepreneurial culture atmosphere. For example, Peking University, Tsinghua University, Fudan University, Shanghai Jiao Tong University, Jilin University and other universities set up a series of courses on innovation and entrepreneurship, hold entrepreneurship salon, organize entrepreneurial design competition, establish the practice bases of entrepreneurship education, and actively create conditions for students to start business.

The top universities in Chinese mainland carry out the teaching reform, which mainly focused on the developmental evaluation, enriched the content of the students 'evaluation, and evaluate the students' academic performance and learning quality comprehensively by multiple indicators. For example, Zhejiang University evaluate five indexes from the first classroom and the second classroom, including: academic performance of the first classroom, research and innovation ability, social practice, social work and recreational activities [6]. And, Nanjing University evaluate the students from two aspects: the daily factual assessment and the final evaluation, including the daily factual assessment, the students' mutual judgment and evaluation of the examination group [7].

\section{Training High-Quality Talent: The Core}

\section{Competitiveness of Undergraduate Education at NCUT}

As a multi-disciplinary university attached to Beijing which combines the natural sciences and engineering with liberal arts, economics, management and law, NCUT upholds the principle of "establishing schools with quality and running schools with distinctive features". In the past 70 years since its establishment, NCUT has formed a distinctive education mechanism and maintained a high-level comprehensive strength in non "211 project" universities, especially in universities of technology. From 2011 to 2016, the position in the Chinese mainland University Rankings rose from 355 th to 311 st, which showed a steady upward trend. The comprehensive strength rankings rose from top $50.28 \%$ to top $43.13 \%$, with the increase of 7.3 pct annually. And further more, the position in the national rankings of talent training rose from 332th to 299th, which rose from top $47.03 \%$ to top $41.47 \%$, with the increase of $5.5 \mathrm{pct}$ annually.

From the perspective of student source quality and indexes of student development, NCUT has higher quality student source of undergraduates. In 2017, the average admission score of science and engineering major in NCUT was 27.49 points higher than that of key university. There were 606 outstanding candidates whose score exceed $110 \%$ or 50 points higher than the admission line of key university, accounting for $25 \%$ of the undergraduate freshmen in school, which is the most over the years. According to the survey of third-party educational quality evaluation agency - MyCOS Data (Beijing) Co., Ltd., the students' of NUCT have high identification degree on the majors and more reasonable career expectations, which maintains a leading position in the same kind of colleges and universities in the country.

From the perspective of the model of talent training and the index of curriculum system, NCUT follows the idea of "people-oriented and teaching students according to their aptitude". After more than a decade of continuous exploration, accumulation and perfection, the education mode of " stratified teaching, distributary training and classified talents" has been formed, the basic curriculum system of stratified teaching, the specialized curriculum system and practical teaching system of distributary training have been established. According to the classification of training objectives, optimize and integrate the professional curriculum system, set up advanced courses based on basic curriculum, practice courses, professional skills certification courses and skills operating training, formulate college students' innovation and entrepreneurship programs and science and technology competition projects, establish high quality campus training base, to train high-quality talents with innovative spirit and international vision, meanwhile having both ability and integrity and strong practical ability, 
which has achieved an effective fit between the effectiveness of school education and the demand of national talents.

From the perspective of the teaching management system and students' demand, NCUT fully respects the students' interests and personal choices, improves the dynamic credit system, makes policies on changing majors, implements recruit students of heavy caliber and cultivation reforms, and constructs a new teaching management mode of "standardization, individuation, humanization and informatization". In terms of graduates employment status satisfaction, the recommendation degree and satisfaction of alma mater, NCUT retains leading position in non "211 project" universities for fourth consecutive year since 2013, cultivates a large number of elite talents, industrial personnel, public servants, celebrities and other outstanding talents.

\section{Conclusion}

The quality of talent training is an important indicator to measure the level of running a university. Combining with the status quo of the top university's core competitiveness and the experience of NCUT in talent training, it is necessary to pay attention to the following four aspects in cultivating the university's core competitiveness:

Firstly, colleges and universities should combine the national and regional development strategies with the needs of social and economic development, make overall plans to optimize school resources, locate accurately and reasonably, form distinctive and differentiated comparative advantages.

Secondly, colleges and universities should focus on talent training and paying attention to teaching students according to their aptitude, and implement mode reform of the talent training.

Thirdly, colleges and universities should perfect the system of practical teaching, increase the proportion of practical teaching, strengthen the construction of practical teaching bases, vigorously carry out subject competitions and scientific research trainings, and enhance students' innovative spirit and practical ability.

Finally, colleges and universities should improve the teaching management, innovate quality assessment and evaluation methods, pay attention to process evaluation and ability evaluation, improve teaching quality.

\section{References}

[1] Prahalad C.K, Hamel G. The core competency of the corporation[J]. Harvard Business Review, 1990(3): 79-91.

[2] Michael E. Porter. The Competitive Advantage of Nations[M].Beijing: Huaxia Press, 2002.

[3] LIU Xiang-bing. Expounding on the Concept of "Core Competence of the University" [J]. Journal of Renmin University of China,2006,(02):143-146.

[4] LAI Die-sheng, Wu Xiang-rong. Discusses the University's Core Competitiveness [J]. Education Research,2002,(07):42-46.

[5] QU Heng-chang. Building Key Competitive Abilities of Universities and Enhancing International Competitive
Advantages of Higher Education in Our Country

[J].Comparative Education Review,2005,(02):80-85.

[6] Zhejiang University Undergraduate Academic Evaluation Methods

[EB/OL].http://bksy.zju.edu.cn/qsxy/redir.php?catalog_i $\mathrm{d}=708777$ \&object_id=709651, 2008-12-30.

[7] Nanjing University Student Handbook [EB/OL].http://jw.nju.edu.cn/pdf/students/stu.pdf, 2012-09-30. 
Recent Developments on Information and

Communication Technology (ICT) Engineering- Meen, Yang \& Zhao ISBN: 978-981-14-2136-5 